\title{
Development of Myeloperoxidase Anti-neutrophil Cytoplasmic Antibody-positive Necrotizing Crescentic Glomerulonephritis in an Elderly Patient with Immunological Kidney Disease
}

\author{
Haruyoshi Yoshida ${ }^{1}$, Naoki Takahashi ${ }^{2}$, Takayasu Horiguchi ${ }^{1}$, Hiroki Yasuhara ${ }^{1}$, \\ Tokuharu Tanaka ${ }^{1}$, Yuhao Chen ${ }^{1}$, Toshikazu Takasaki ${ }^{1}$, Hitokazu Tsukao ${ }^{1}$, Michiko Yoshida ${ }^{1}$, \\ Satoshi Kawakami ${ }^{3}$, Makoto Ohta ${ }^{4}$, Hironobu Naiki ${ }^{5}$, Satoshi Konishi ${ }^{6}$, \\ Isao Ito $^{6}$ and Masayuki Iwano ${ }^{2}$
}

\begin{abstract}
:
A 78-year-old man presented with hypercalcemia and renal disease with high serum IgG4 and positive myeloperoxidase anti-neutrophil cytoplasmic antibody (MPO-ANCA), exhibiting sarcoidosis-like chest findings. A renal biopsy revealed tubulointerstitial nephritis, membranous nephropathy (MN), and sub-capsular lymphoid aggregates without fulfilling the diagnostic criteria of IgG4-related disease or sarcoidosis. Steroid therapy ameliorated the serological and renal abnormalities. After 5 years, following gradual increases in the neutrophil count and upper respiratory infection (URI), necrotizing crescentic glomerulonephritis (NCGN) developed with an increased serum MPO-ANCA level. These results suggest that in the presence of MPOANCA in immune senescence, the persistent neutrophil increase with URI may lead to the development of NCGN.
\end{abstract}

Key words: hypercalcemia, IgG4-RKD, immune senescence, lymphoid aggregates, membranous nephropathy, sarcoidosis

(Intern Med Advance Publication)

(DOI: 10.2169/internalmedicine.7252-21)

\section{Introduction}

Clinical surveys on anti-neutrophil cytoplasmic antibody (ANCA)-associated vasculitis revealed geographic and racial differences in the prevalence with the predominance of myeloperoxidase (MPO)-ANCA over proteinase 3 (PR3)ANCA in Japan, whereas the opposite findings have been reported in Europe and North America. ANCA-positive glomerulonephritis (GN) is commonly diagnosed in patients older than 50 years of age and thereafter becomes more prevalent with aging (1-3). In a large cohort study in the
United States on renal biopsy samples obtained from patients older than 80 years, ANCA-associated pauci-immune GN was the most frequent diagnosis, and the number of patients with MPO-ANCA was more than 3-fold higher than those with PR3-ANCA (4). Since MPO-ANCA is an autoantibody that is mostly detected in elderly populations, and aging-associated immune dysfunction increases susceptibility to various autoimmune diseases (5), the co-occurrence of MPO-ANCA with other immunological diseases is expected (6). We herein report the development of MPOANCA-positive pauci-immune necrotizing crescentic glomerulonephritis (NCGN) during the remission of tubu-

${ }^{1}$ Department of Internal Medicine, Sugita-Genpaku Memorial Obama Municipal Hospital, Japan, ${ }^{2}$ Department of Nephrology, University of Fukui, Japan, ${ }^{3}$ Department of Diagnostic Radiology, Sugita-Genpaku Memorial Obama Municipal Hospital, Japan, ${ }^{4}$ Department of Pathology, Hikone Municipal Hospital, Japan, ${ }^{5}$ Department of Molecular Pathology, University of Fukui, Japan and ${ }^{6}$ Department of Respiratory Medicine, Kyoto University Hospital, Japan

Received: February 4, 2021; Accepted: May 7, 2021; Advance Publication by J-STAGE: June 19, 2021

Correspondence to Dr. Haruyoshi Yoshida, yoshida@obamahp-wakasa.jp 


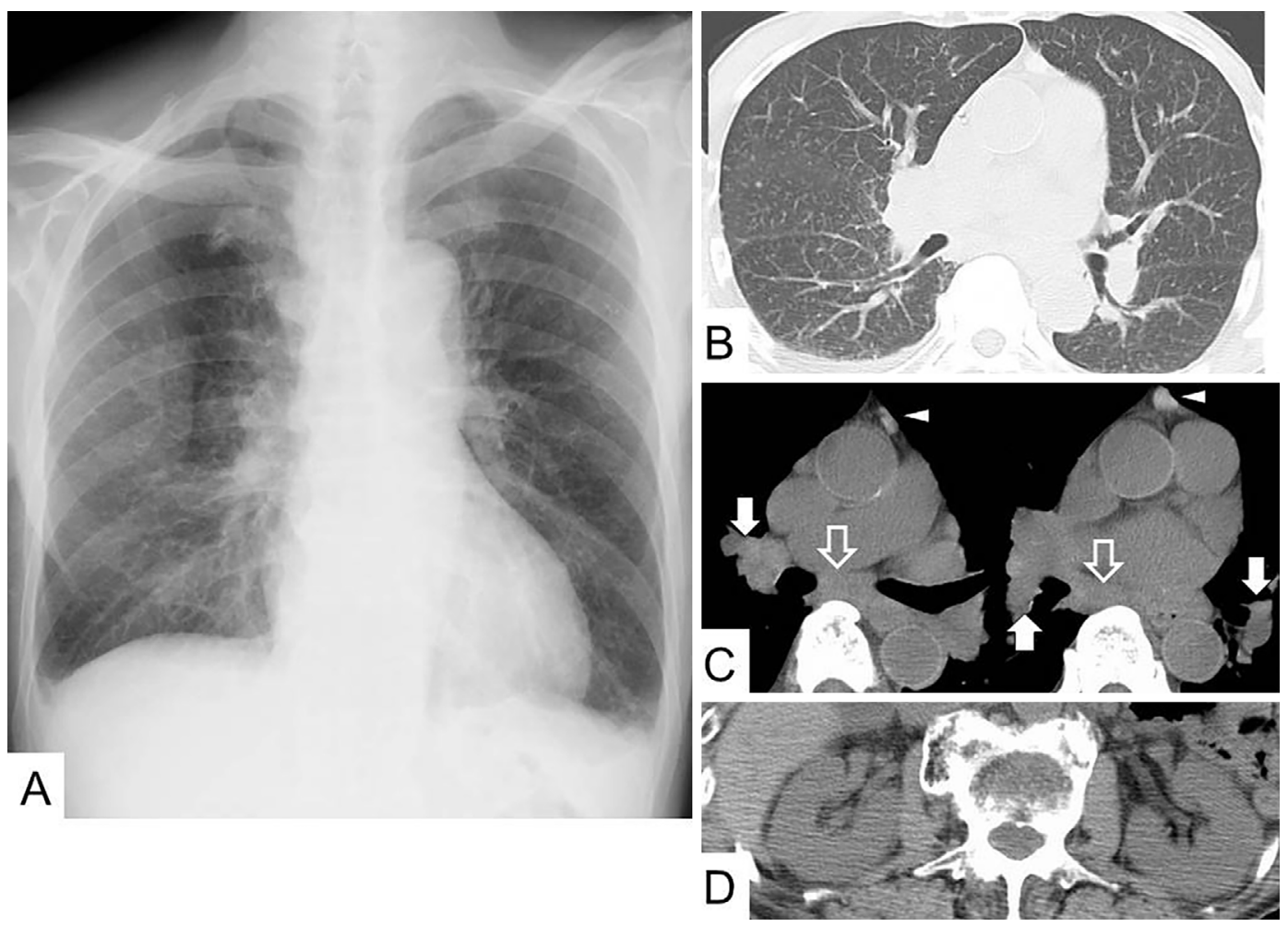

Figure 1. Radiographic findings in the first admission. A: Chest $\mathrm{X}$ ray showing diffuse fine nodular shadows with dull costo-phrenic angles. B: Computed tomography (CT) showing the diffuse distribution of fine nodules. C: CT images showing bilateral hilar lymph node swelling (closed arrows), mediastinal lymph node swelling (open arrows) and an anterior mediastinal nodule (arrow heads), with small volume of bilateral pleural effusion. D: A CT image showing mild to moderate swelling of both kidneys, within the normal size range.

lointerstitial nephritis (TIN) with hypercalcemia suggesting sarcoidosis and plasma cell infiltration diagnosed as possible IgG4-related kidney disease (IgG4-RKD), associated with membranous nephropathy (MN). The results of this retrospective investigation suggest that a persistent increase of neutrophils associated with MPO-ANCA in immune senescence and incidental upper respiratory infection may have predisposed our patient to develop MPO-ANCA-associated NCGN, probably by exposing MPO antigen to anti-MPO antibodies as well as to memory $\mathrm{T}$ cells for the antibody production.

\section{Case Report}

A 78-year-old man with a 3-year history of right hemiparesis visited Department of Internal Medicine, Obama Municipal Hospital in October 2013 with anorexia symptoms experienced for the past 2 weeks. He had a past history of cerebral infarction in the left basal ganglia which had developed in November 2010. He had no allergic history, nor dry eye or dry mouth suggesting Sjögren syndrome. Ophthalmologic examinations did not show any specific changes on ocular surface or ocular fundus. He had been taking daily medications of clopidogrel sulfate $75 \mathrm{mg}$, rabeprazole sodium $10 \mathrm{mg}$, allopurinol $200 \mathrm{mg}$ and zopicloban $7.5 \mathrm{mg}$ for the past 3 years, without any adverse events.
His blood pressures were 163/91. Chest X-ray and computed tomography (CT) showed diffuse reticular-granular shadows in the lungs, bilateral hilar-mediastinal lymphadenopathy (BHL) and small volume of bilateral pleural effusion with a small nodule in the anterior mediastinum (Fig. 1A-C). On abdomen CT, both kidneys showed mild to moderate swelling within the normal size range (Fig. 1D), with a fine stone in the right kidney (figure, not shown). The CT images showed degenerative changes of thoracic and lumbar spine with no findings of osteolysis or ossification (figure, not shown). 18-Fluorodeoxyglucose-positron emission tomography (FDG-PET)/CT images revealed mild positivity in the mediastinal and bilateral lymph nodes, but not in the anterior mediastinal nodule, suggesting a thymic cyst or benign thymoma (figure, not shown). Tuberculosis (TB) was excluded based on a negative sputum culture and T-SPOT.TB $^{\circledR}$ (interferon- $\gamma$ releasing assay). Electrocardiography showed a complete right bundle branch block. The blood examinations 9 months before the onset of the present illness showed WBC $3,850 / \mu \mathrm{L}$ and $\mathrm{Hb} 11.4 \mathrm{~g} / \mathrm{dL}$, with normal levels of aspartate aminotransferase (AST) of $26 \mathrm{IU} / \mathrm{L}$, alkaline phosphatase (ALP) of $287 \mathrm{IU} / \mathrm{L}$, calcium $9.2 \mathrm{mg} /$ $\mathrm{dL}$, and creatinine $(\mathrm{Cr})$ of $0.81 \mathrm{mg} / \mathrm{dL}$ As shown in the column for the first biopsy in the Table, urinalysis revealed proteinuria of $1.66 \mathrm{~g} /$ day, occult blood $2+$, and a high level of N-acetyl- $\beta$-D-glucosaminidase (NAG). A serological ex- 
Table. Laboratory Data from $1^{\text {st }}\left(\right.$ November 2013) and $2^{\text {nd }}($ October 2018) Renal Biopsies.

\begin{tabular}{|c|c|c|c|c|c|}
\hline Variable & 1 stBiopsy & $2^{\text {nd }}$ Biopsy & Variable & $1^{\text {stBiopsy }}$ & $2^{\text {nd }}$ Biopsy \\
\hline$<$ Urinalysis $>$ & & & HDL-cholesterol & $33 \mathrm{mg} / \mathrm{dL}$ & $37 \mathrm{mg} / \mathrm{dL}$ \\
\hline $\mathrm{pH}$ & 7.0 & 5.5 & Total protein & $7.5 \mathrm{~g} / \mathrm{dL}$ & $6.1 \mathrm{~g} / \mathrm{dL}$ \\
\hline Specific gravity & 1.010 & 1.005 & Albumin & $3.4 \mathrm{~g} / \mathrm{dL}$ & $3.2 \mathrm{~g} / \mathrm{dL}$ \\
\hline \multirow[t]{2}{*}{ Protein } & $92 \mathrm{mg} / \mathrm{dL}$ & $104 \mathrm{mg} / \mathrm{dL}$ & Sodium & $141 \mathrm{mEq} / \mathrm{L}$ & $136 \mathrm{mEq} / \mathrm{L}$ \\
\hline & $1.66 \mathrm{~g} /$ day & $1.61 \mathrm{~g} /$ day & Potassium & $3.2 \mathrm{mEq} / \mathrm{L}$ & $3.2 \mathrm{mEq} / \mathrm{L}$ \\
\hline Occult blood & $2+$ & $3+$ & Chloride & $101 \mathrm{mEq} / \mathrm{L}$ & $102 \mathrm{mEq} / \mathrm{L}$ \\
\hline Sediment RBC & 20-29/HPF & $>100 / \mathrm{HPF}$ & Calcium & $12.0 \mathrm{mg} / \mathrm{dL}$ & $6.3 \mathrm{mg} / \mathrm{dL}$ \\
\hline Sediment WBC & 1-4 /HPF & 10-19/HPF & Adjusted calcium & $12.6 \mathrm{mg} / \mathrm{dL}$ & $7.1 \mathrm{mg} / \mathrm{dL}$ \\
\hline Sediment Cast (H/G) & $5-10 / 1-4$ & $20-29 /-$ & Phosphorus & $2.8 \mathrm{mg} / \mathrm{dL}$ & $3.0 \mathrm{md} / \mathrm{dL}$ \\
\hline $\mathrm{NAG}^{\mathrm{a}}(<5.0)$ & $11.8 \mathrm{U} / \mathrm{L}$ & n.d $\mathrm{d}^{\mathrm{b}}$ & Creatinine & $1.35 \mathrm{mg} / \mathrm{dL}$ & $3.17 \mathrm{mg} / \mathrm{dL}$ \\
\hline$<\mathrm{CBC}>$ & & & Urea nitrogen & $17.0 \mathrm{mg} / \mathrm{dL}$ & $51.3 \mathrm{mg} / \mathrm{dL}$ \\
\hline WBC & $4,710 / \mu \mathrm{L}$ & $6,850 / \mu \mathrm{L}$ & Uric acid & $6.5 \mathrm{mg} / \mathrm{dL}$ & $5.5 \mathrm{mg} / \mathrm{dL}$ \\
\hline $\mathrm{RBC}$ & $281 \times 10^{4} / \mu \mathrm{L}$ & $374 \times 10^{4} / \mu \mathrm{L}$ & Sugar & $95 \mathrm{mg} / \mathrm{dL}$ & $104 \mathrm{mg} / \mathrm{dL}$ \\
\hline Hemoglobin & $9.1 \mathrm{~g} / \mathrm{dL}$ & $11.8 \mathrm{~g} / \mathrm{dL}$ & $<$ Infection and Immu & $\log y>$ & \\
\hline Hematocrit & $26.7 \%$ & $34.5 \%$ & Procalcitonin & $<0.5 \mathrm{ng} / \mathrm{mL}$ & $<0.5 \mathrm{ng} / \mathrm{mL}$ \\
\hline Platelet & $18.3 \times 10^{4} / \mu \mathrm{L}$ & $32.8 \times 10^{4} / \mu \mathrm{L}$ & $\mathrm{CRP}(<0.5)$ & $0.20 \mathrm{mg} / \mathrm{dL}$ & $4.67 \mathrm{mg} / \mathrm{dL}$ \\
\hline Neutrophil $(1,640-5,950)$ & $2,070 / \mu \mathrm{L}$ & $5,360 / \mu \mathrm{L}$ & $\mathrm{IgG}$ & $2,131 \mathrm{mg} / \mathrm{dL}$ & $1,550 \mathrm{mg} / \mathrm{dL}$ \\
\hline Lymphocyte $(1,120-3,330)$ & $1,800 / \mu \mathrm{L}$ & $800 / \mu \mathrm{L}$ & IgA & $217 \mathrm{mg} / \mathrm{dL}$ & $203 \mathrm{mg} / \mathrm{dL}$ \\
\hline Monocyte (180-610) & $330 / \mu \mathrm{L}$ & $600 / \mu \mathrm{L}$ & $\operatorname{IgM}$ & $68 \mathrm{mg} / \mathrm{dL}$ & $59 \mathrm{mg} / \mathrm{dL}$ \\
\hline Eosinophil (20-480) & $480 / \mu \mathrm{L}$ & $70 / \mu \mathrm{L}$ & $\operatorname{IgE}(<170)$ & $4,243 \mathrm{IU} / \mathrm{mL}$ & $117 \mathrm{IU} / \mathrm{mL}$ \\
\hline Basophil (10-100) & $30 / \mu \mathrm{L}$ & $20 / \mu \mathrm{L}$ & IgG4 (4.8-105) & $253 \mathrm{mg} / \mathrm{dL}$ & $74.5 \mathrm{mg} / \mathrm{dL}$ \\
\hline$<$ Biochemistry $>$ & & & $\operatorname{sIL}^{2} R^{\mathrm{c}}(145-519)$ & $1,758 \mathrm{U} / \mathrm{mL}$ & $676 \mathrm{U} / \mathrm{mL}$ \\
\hline Total bilirubin $(0.2-1.2)$ & $0.8 \mathrm{mg} / \mathrm{dL}$ & $0.9 \mathrm{mg} / \mathrm{dL}$ & $\mathrm{CH}_{50}$ & n.d. & $>60.0$ \\
\hline $\operatorname{AST}(8-38)$ & $47 \mathrm{IU} / \mathrm{L}$ & 17 IU/L & C3 (86-160) & $76 \mathrm{mg} / \mathrm{dL}$ & $108 \mathrm{mg} / \mathrm{dL}$ \\
\hline ALT (4-44) & $12 \mathrm{IU} / \mathrm{L}$ & $7 \mathrm{IU} / \mathrm{L}$ & C4 (17-45) & $22 \mathrm{mg} / \mathrm{dL}$ & $38 \mathrm{mg} / \mathrm{dL}$ \\
\hline ALP (104-338) & $1,180 \mathrm{IU} / \mathrm{L}$ & $218 \mathrm{IU} / \mathrm{L}$ & $\mathrm{ANA}^{\mathrm{d}}$ & n.d. & $40+, \mathrm{Homo}^{\mathrm{e}}$ \\
\hline LD (106-211) & $310 \mathrm{IU} / \mathrm{L}$ & $208 \mathrm{IU} / \mathrm{L}$ & Anti-dsDNA IgG & $<10 \mathrm{IU} / \mathrm{mL}$ & n.d. \\
\hline CK (56-244) & 177 IU/L & 159 IU/L & MPO-ANCA $(<3.5)$ & $16.3 \mathrm{U} / \mathrm{mL}$ & $>300 \mathrm{U} / \mathrm{mL}$ \\
\hline Total cholesterol & $162 \mathrm{mg} / \mathrm{dL}$ & $165 \mathrm{mg} / \mathrm{dL}$ & PR3-ANCA $(<1.0)$ & $<1.0 \mathrm{U} / \mathrm{mL}$ & $<1.0 \mathrm{U} / \mathrm{mL}$ \\
\hline Triglycerides & $65 \mathrm{mg} / \mathrm{dL}$ & $67 \mathrm{mg} / \mathrm{dL}$ & Anti-GBM $(<2.0)$ & $<2.0 \mathrm{U} / \mathrm{mL}$ & n.d. \\
\hline
\end{tabular}

Data obtained approximately one month before biopsy are shown to

exclude the effects of the immunosuppressive treatment. Reference ranges are shown in the parentheses of variables, except for the sediment

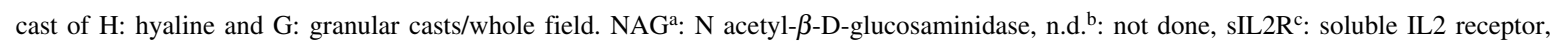
ANA $^{\mathrm{d}}$ : anti-nuclear antibody, Homo ${ }^{\mathrm{e}}$ : Homogenous

amination showed a high adjusted value for calcium of 12.6 $\mathrm{mg} / \mathrm{dL}$ and elevated $\mathrm{Cr}$ level of $1.41 \mathrm{mg} / \mathrm{dL}$, with high $\mathrm{IgG}$, IgG4, IgE, soluble interleukin 2 receptor (sIL2R), AST,ALP, and MPO-ANCA levels and a low C3 level. Negative serum findings were obtained for angiotensin-converting enzyme (ACE), monoclonal $\gamma$-globulin, procalcitonin, CRP, PR3ANCA, the anti-dsDNA antibody, and anti-glomerular basement membrane (GBM) antibody. Regarding hypercalcemia, elevations were observed in the urinary Ca level $(304 \mathrm{mg}$ / day, reference range; $100-300 \mathrm{mg} /$ day) and urinary $\mathrm{Ca} / \mathrm{Cr}$ ratio (0.258, reference range; 0.05-0.15). His serum intact parathyroid hormone (PTH) level was low at $7.3 \mathrm{pg} / \mathrm{mL}$ (reference range; $10-65 \mathrm{pg} / \mathrm{mL}$ ) and the PTH-related peptide was negative. His serum $1 \alpha-25$ - dihydroxy vitamin D3 level had decreased to $8.6 \mathrm{pg} / \mathrm{mL}$ (reference range; 20.0-60.0 pg/ $\mathrm{mL})$.

The first renal biopsy in November 2013 showed TIN and $\mathrm{MN}$ with the scattered interstitial infiltration of lymphocytes, plasma cells, and a few eosinophils as well as the focal tubular deposition of calcium (Fig. 2A, B, E-G). There were no findings of noncaseating epithelioid granuloma formation, which is characteristic of sarcoidosis, or interstitial storiform fibrosis specific to IgG4-RKD. Immunofluorescent (IF) staining showed granular IgG and C3 deposition along glomerular capillaries. Immunoenzyme staining also revealed fine granular IgG, but not IgG4, deposition along glomerular capillaries (Fig. 2G). IgG- and IgG4-positive plasma cells were observed in the interstitium, with approximately $30 \%$ positivity for IgG4 among IgG-positive cells and with more than 10 IgG4-positive cells/high power field (HPF) (Fig. 2C, D). Staining for the M-type phospholipase A2 receptor (PLA2R) was negative (Fig. 2H). In addition, focal lymphocyte aggregates adjacent to a small vein were located in the sub-capsular regions (Fig. 2I, J). A lymphoid follicular structure with interstitial cells surrounding a high endothelial venule (HEV)-like vessel contained clusters of IgGpositive cells, but rarely IgG4-positive cells (Fig. 2J-L).

Since hypercalcemia and renal dysfunction worsened despite the infusion of saline and furosemide, the administration of prednisolone (PSL) was initiated at $20 \mathrm{mg} /$ day in 

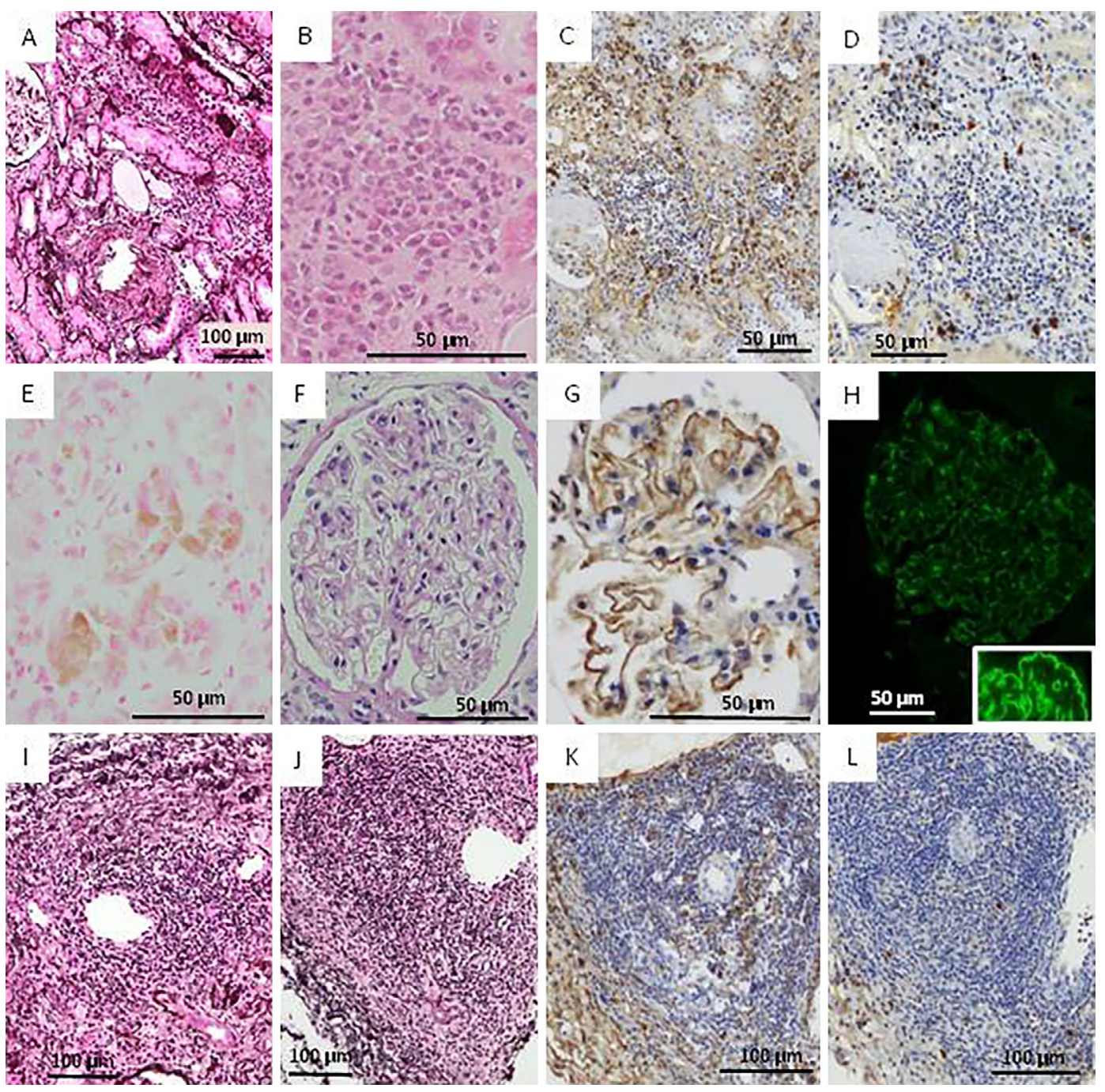

Figure 2. The first renal biopsy in November 2013 showed 30 glomeruli (GL) with minimal changes and 6 with global sclerosis. In the tubulointerstitial region, areas of interstitial mononuclear cell infiltration were focally observed with tubular atrophy [A; periodic acid-Schiff (PAS)-methenamine (PASM) staining]. B: The interstitial infiltration of lymphocytes and plasma cells with a small number of eosinophils (Hematoxylin and Eosin staining). C: The focal interstitial infiltration of IgG-positive plasma cells by immunoenzyme staining. D: Interstitial IgG4-positive cells by immunoenzyme staining. Parts $\mathrm{C}$ and $\mathrm{D}$ are serial sections. The IgG4+/IgG+cell ratio was approximately 30\%. E: Proximal tubules were focally positive with a brown color by Kossa staining for calcium. F: An enlarged glomerulus with membranous thickening (PAS staining). G: Fine granular IgG distribution along glomerular capillaries by immunoenzyme staining. H: Negative glomerular staining against the M-type phospholipase A2 receptor by an immunofluorescent method. A positive control is shown in the insert. I: Sub-capsular lymphoid aggregates surrounding a small vein (PASM staining). J: Subcapsular lymphoid follicular tissue adjacent to a small vein (PASM staining). K: Clusters of IgGpositive cells in lymphoid tissue with a high endothelial venule (HEV) -like vessel in the center (immunoenzyme staining). L: A few IgG4-positive cells in lymphoid tissue with a HEV-like vessel in the center (immunoenzyme staining). Parts J-L are serial sections. The scale is shown with a scale bar at the bottom in each part.

November 2013 and thereafter was gradually tapered to a maintenance dose of $2.5 \mathrm{mg}$ from January 2016 (Fig. 3). Hypercalcemia and the high $\mathrm{Cr}$ level completely recovered after 2 weeks of PSL therapy, and this was followed by negative urinary occult blood and normal blood pressure. In response to PSL, the mild increase of the serum AST level of $47 \mathrm{IU} / \mathrm{L}$ was normalized in 2 weeks and the high serum
ALP level of 1,180 IU/L gradually decreased to within the reference range after 6 months. However, approximately 15 months was required to achieve negative urinary protein in March 2015 despite the early amelioration from 3+ to 1+ after 4 weeks of PSL therapy. The patient did not subsequently exhibit any clinical signs or renal symptoms in outpatient consultations every 1-2 months until 2017. 


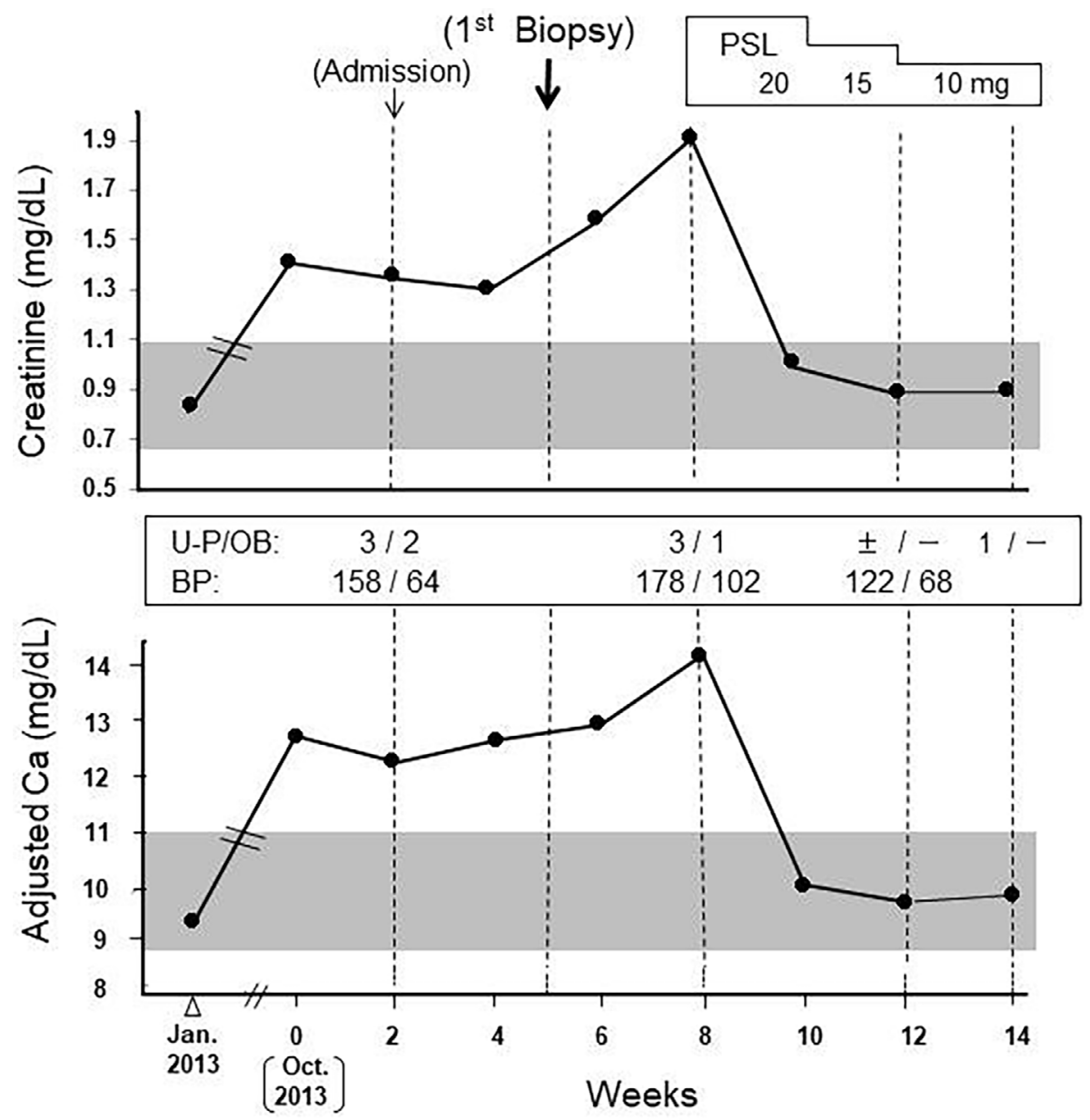

Figure 3. Sequential changes in serum creatinine (upper part) and adjusted serum calcium (Ca) (lower part) in the first renal biopsy. Changes in urinary protein and occult blood (U-P/OB) and blood pressure (BP) are shown in the middle part. Oral prednisolone (PSL) administration from 20 to $10 \mathrm{mg} /$ day is depicted at the top. Shaded areas indicate the reference ranges of each measurement.

Fig. 4 shows the clinical and laboratory courses from September 2016 (0 month) to September 2018 (24 months) leading to the development of MPO-ANCA-associated NCGN. At 0 month, MPO-ANCA was negative, similar to that in May and December 2014, with a normal serum $\mathrm{Cr}$ level $(0.83 \mathrm{mg} / \mathrm{dL})$ and normal urinalysis. At 6 months, peak increases in WBC count to 7,160 and neutrophil count to 4,790 with an elevated monocyte count of $880 / \mu \mathrm{L}$ were observed with a normal serum $\mathrm{Cr}$ level $(0.79 \mathrm{mg} / \mathrm{dL})$ and normal urinalysis. At 10 months, WBC and neutrophil counts decreased to trough levels of 4,740 and 2,170, respectively, with the monocyte count remaining at nearly the upper limit of the reference range. At 14 months, an ocular examination for the blurred vision showed moderate cataracts of both eyes but no evidence of uveitis. At 15 months, serum $1 \alpha-25-$ dihydroxy vitamin D3 level was increased to $67.0 \mathrm{pg} / \mathrm{mL}$ with a lower adjusted $\mathrm{Ca}$ of $8.7 \mathrm{mg} / \mathrm{dL}$. At 16 months, CT images showed persisting chest findings of BHL and small nodular lung opacity although pleural effusion and kidney swelling were not observed after the steroid therapy (figure, not shown). Bronchoscopy performed 3 weeks later revealed a CD4/CD8 ratio of 1.44 , with macrophages $86 \%$, neutrophils $9 \%$ and lymphocytes $5 \%$ in bronchoalveolar lavage fluid (BALF) from right $\mathrm{B}^{5}$, while transbronchial lung biopsy from right $\mathrm{B}^{2}, \mathrm{~B}^{3}$ and $\mathrm{B}^{8}$ showed non-specific inflammation without epithelioid granuloma or IgG4-positive plasma cells. At 17 months, the only abnormal serological result of a high MPO-ANCA titer of $160 \mathrm{U} / \mathrm{mL}$ with a normal serum $\mathrm{Cr}$ level of $0.85 \mathrm{mg} / \mathrm{dL}$ and normal urinalysis was observed in the middle of increases in the WBC and neutrophil counts. At 20 months, peak increases were observed in the WBC count to 7,880 and the neutrophil count to 6,090 with a CRP level of $0.65 \mathrm{mg} / \mathrm{dL}$, which were accompanied by slight abnormalities in urinary protein $( \pm)$ and occult blood 1+. One month later, the patient unexpectedly developed an upper respiratory infection with a cough, rhinorrhea, and a sore throat, and, thus, clarithromycin was administered for 7 days. Throughout the course, the changes observed in the neutrophil count were parallel with those in the WBC count and greater than those in WBC.

At 24 months (September 2018), the patient developed general malaise and leg edema with a serum $\mathrm{Cr}$ level of $1.99 \mathrm{mg} / \mathrm{dL}$, urinary proteinuria $2+$, and occult blood $3+$. A serological examination showed a high CRP level of 4.67 $\mathrm{mg} / \mathrm{dL}$ without an increase in the serum level of procalcitonin and, thus, the dose of PSL administered was increased 


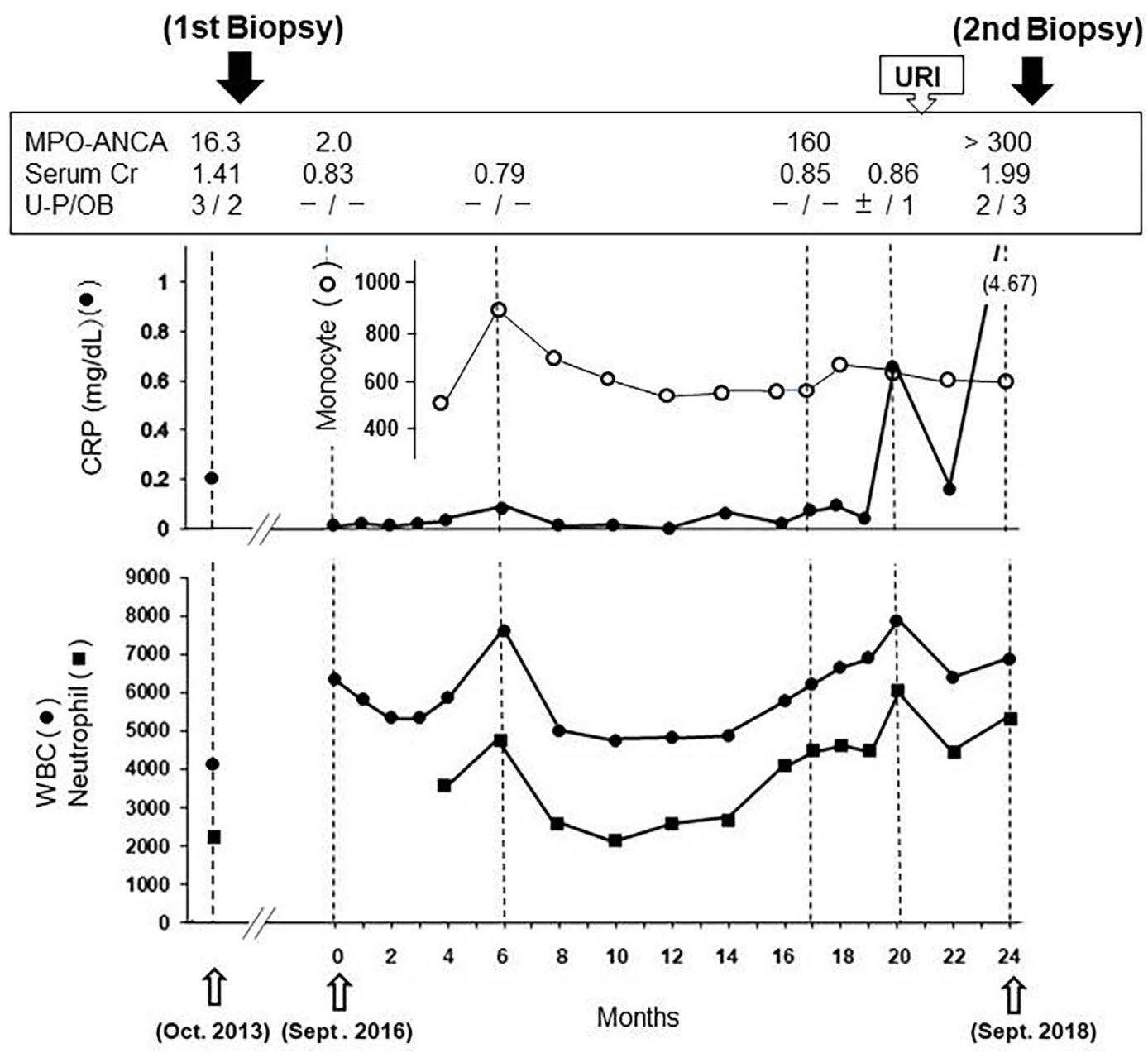

Figure 4. The upper part of the graph shows sequential changes in serum CRP (closed circle) with monocyte counts (open circle), and the lower part shows those of WBC (closed circle) and neutrophils (closed rectangle) between September 2016 (0 month) and September 2018 (24 months). At the top, changes in serum MPO-ANCA, serum creatinine $(\mathrm{Cr})$, and the grades of urinary protein and occult blood (U-P/OB) are shown in the period from the first to second renal biopsy. URI means upper respiratory infection.

to $20 \mathrm{mg} /$ day. A later report from the clinical laboratory showed MPO-ANCA $>300 \mathrm{U} / \mathrm{mL}$ (the column for 2 nd biopsy in the Table). Three weeks later, the patient was admitted and received an infusion of cyclophosphamide $(750 \mathrm{mg} /$ day) and methylprednisolone pulse therapy ( $1 \mathrm{~g} \times 3$ days $)$. In October with a serum $\mathrm{Cr}$ level of $4.01 \mathrm{mg} / \mathrm{dL}$. A second renal biopsy performed in the middle October 2018 showed NCGN with $62 \%$ crescentic glomeruli and $\mathrm{MN}$ in the remaining glomeruli (Fig. 5A, D-F). The interstitial infiltration of IgG4-positive plasma cells was as mild with an IgG4/IgG ratio of $20 \%$ and the cell number was less than 10/HPF (Fig. 5B, C). There were no findings to indicate noncaseating epithelioid granuloma or interstitial storiform fibrosis. In January 2019, the attenuation of renal symptoms was achieved with consecutive PSL therapy: a serum $\mathrm{Cr}$ level of $1.45 \mathrm{mg} / \mathrm{dL}$, proteinuria $( \pm)$ and urinary occult blood $3+$, with MPO-ANCA of $35.8 \mathrm{U} / \mathrm{mL}$, a CRP level of $0.53 \mathrm{mg} /$ $\mathrm{dL}$, WBC count of 5,600, and neutrophil count of 4,040. However, 3 months later, the patient died of septicemia associated with cholecystitis and an iliopsoas muscle abscess caused by a urinary tract infection with extended spectrum $\beta$-lactamase-positive Escherichia coli.

\section{Discussion}

In his first admission, the patient showed BHL, diffuse reticular-granular lung infiltration, and various serological abnormalities, including high levels of calcium, ALP, sIL2R, $\mathrm{IgG}, \mathrm{IgG} 4$, and $\mathrm{IgE}$ and positivity for MPO-ANCA with a low C3 level. The pulmonary findings observed in addition to hypercalcemia and high serum levels of ALP and sIL2R are hallmarks of sarcoidosis $(7,8)$, However, noncaseating epithelioid granuloma, which is an essential pathological lesion in sarcoidosis, was not detected in either lung or renal biopsies, and the diagnostic markers of a high CD4/CD8 ratio >3.5 and high serum level of ACE were not present (9). Therefore, the diagnosis was suspected sarcoidosis. Hypercalcemia and TIN responded well to a moderate dose of PSL as often observed in renal sarcoidosis. Furthermore, in the absence of any apparent osteogenic disorder, the steroid 

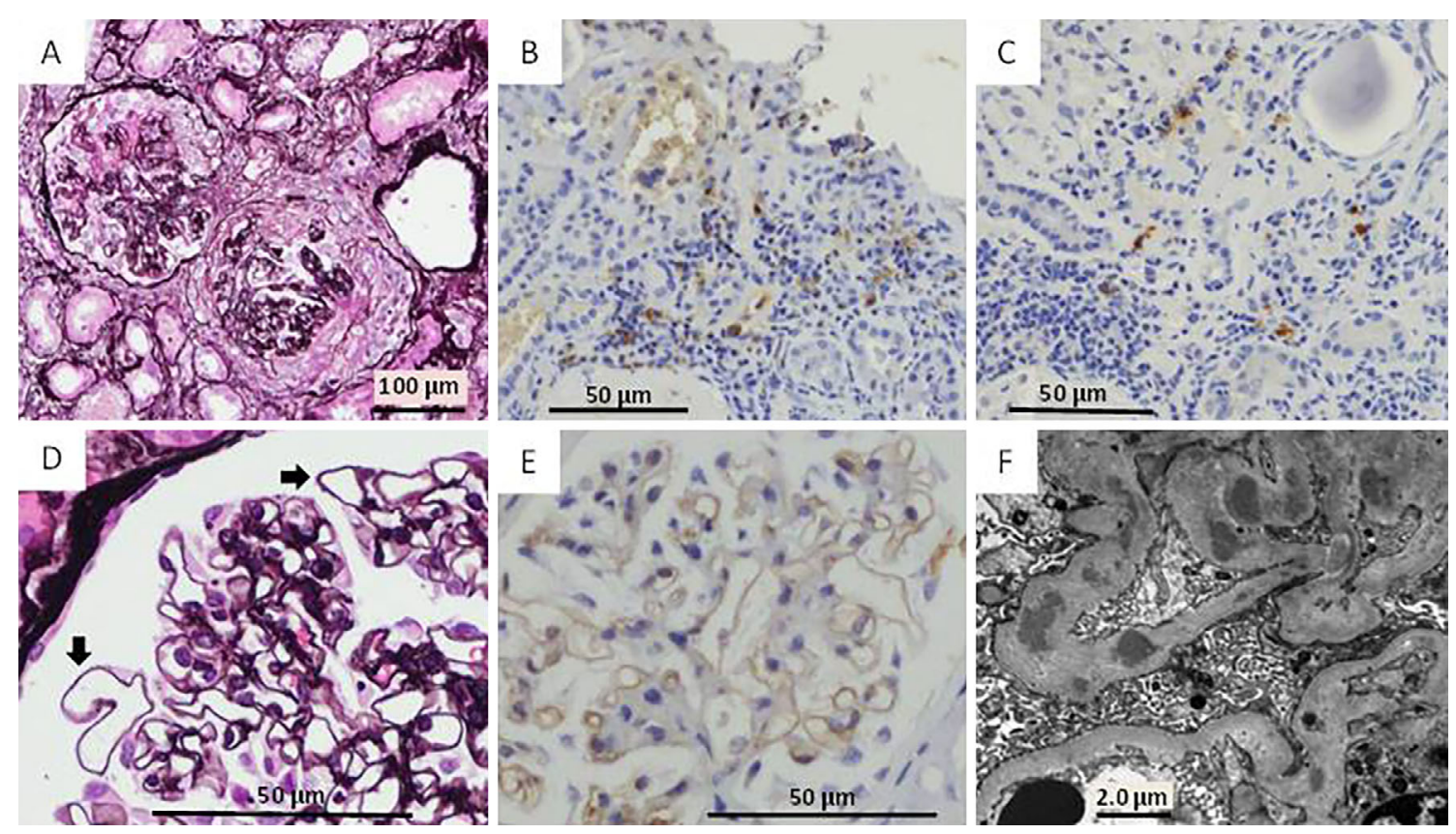

Figure 5. In the second biopsy in November 2018, 21 glomeruli (GL) were obtained, 8 of which showed global or severe sclerosis. In the remaining $13 \mathrm{GL}, 8(62 \%)$ showed fibrocellular crescent formation with 2 exhibiting fibrinoid necrosis (A, PASM staining). Partial tubular atrophy with interstitial fibrosis and the focal infiltration of lymphocytes and plasma cells were observed in the tubulointerstitial region. There were no findings of peritubular capillaritis. B: Focal interstitial infiltration of IgG-positive plasma cells by immunoenzyme staining. C: Interstitial IgG4-positive plasma cells by immunoenzyme staining. Parts $B$ and $C$ are serial sections. The ratio of IgG4-positive cells/IgG-positive cells was approximately 20\%. D: Epimembranous spike formation in some glomerular capillaries (arrows, PASM staining). E: Fine granular IgG distribution along the glomerular capillaries by immunoenzyme staining. F: Intramembranous dense deposits in the glomerular capillaries by electron microscopy. The scale is shown with a scale bar at the bottom in each part.

responsiveness of the high serum ALP level with a mild increase of the AST level thus suggesting a diagnosis of hepatic sarcoidosis $(8,10)$. Since serum sIL2R in sarcoidosis is derived from the cell surface of activated helper T1 (Th1) cells, a high level of sIL2R may be related to the proliferation of macrophages, which contributes to the formation of granuloma (9). In addition, the proliferation of macrophages is presumed not only based on a high macrophage ratio in BALF, but also hypercalcemia, which is derived from high 1 $\alpha$-25-dihydroxy vitamin D3 levels by $1 \alpha$-hydroxylase secreted from activated macrophages (11). In the present case, the decreased serum $1 \alpha$-25-dihydroxy vitamin D3 level in the first admission may have been attributed to inhibited synthesis by a diseased kidney with tubular dysfunction. Its level subsequently increased in the convalescent phase without renal symptoms. With regard to the differential diagnosis of immunological TIN, Sjögren syndrome and tubulointerstitial nephritis and uveitis (TINU) syndrome should be considered. However, the lack of sicca syndrome and uveitis by ophthalmologic examinations in this case did not support the diagnosis of these syndromes. In addition, anti-SSA and anti-SSB antibodies specific for Sjögren syndrome later measured on a preserved serum sample obtained at the second biopsy were negative. Instead, the renal finding of TIN and the serological results of high $\operatorname{IgG} 4, \operatorname{IgE}$, and sIL2R levels in addition to pulmonary findings and kidney swelling supported the diagnosis of $\operatorname{IgG} 4-\operatorname{RKD}(12,13)$. However, a renal biopsy did not fulfil the requirements for the definite criteria, namely, the $\mathrm{IgG} 4 / \mathrm{IgG}$ plasma cell ratio more than $40 \%$ and interstitial storiform fibrosis, with the ultimate diagnosis of possible IgG4-RKD (12).

Therefore, the characteristic disease profile at the first admission was summarized as the co-expression of partial diagnostic markers of different disease categories, including sarcoidosis, IgG4-RKD, and MPO-ANCA-related NCGN without histological confirmation. Previous studies on the age of onset of these diseases in Japan reported that sarcoidosis has two peaks at 20-29 years and older than 50 years (7), the mean age of IgG4-RKD was 63.7 years (12), and the mean age of ANCA-related GN was 69.7 years (3). In a recent Japanese study on the prevalence of elevated serum IgG4 levels in 93 patients with sarcoidosis-like chest findings, which included 49 definite cases and 44 suspected cases, the suspected group showed a higher prevalence of elevated IgG4 levels (13.6\%) with an older mean age $(56.3$ years) than the definite group ( $4.1 \%$ and 47.0 years, respectively), thus suggesting the high frequency of the cooccurrence in the older age (14). Therefore, the various im- 
munological abnormalities of lymphoid proliferation, polyclonal IgG increases with high IgG4 levels, and the autoantibody production of MPO-ANCA with later positivity for antinuclear antibodies seem to reflect immune senescence in the elderly, perceived as T-cell dysfunction in the acquired immune response, low-grade sustained inflammation, and autoantibody production (5). These immune abnormalities may not manifest as a pathological disease without a triggering factor.

Previous studies reported that $\mathrm{MN}$ developed in association with IgG4-RKD or sarcoidosis $(15,16)$. Recent findings on glomerular PLA2R immunostaining may contribute to the discrimination of secondary $\mathrm{MN}$ associated with IgG4RKD or sarcoidosis from idiopathic MN. Idiopathic $\mathrm{MN}$ was previously described as PLA2R-positive in approximately $70 \%$ of $\mathrm{MN}$ cases (17), while $\mathrm{MN}$ associated with active sarcoidosis was reported to be positive in 56\% (5/9 cases) (16). In contrast, PLA2R staining was negative in all 13 cases of MN with $\operatorname{IgG} 4-\operatorname{RKD}(15,18)$. Therefore, the negative PLA2R staining observed in the present case was not decisive for a diagnosis of secondary MN. Since MN was initially associated with suspected sarcoidosis and/or possible IgG4-RKD and was later observed with NCGN, it may have developed based on aging-associated immune dysfunction. It is important to note that sub-capsular focal lymphoid aggregates in the first biopsy were observed independently of interstitial cellular infiltration containing many $\operatorname{IgG}$ 4-positive cells. Lymphoid follicular tissue encircling a HEV-like vessel contained IgG-positive cells, but rarely showed positivity for IgG4. Therefore, these lymphoid aggregates may be regarded as a senescence-associated immune abnormality because the presence of different stages of tertiary lymphoid tissues, such as dense clusters of lymphocytes and lymphoid follicles, were recently characterized in aged, but not young, kidneys with chronic inflammation (19).

It seems likely that the circulating monocytic increase is attributed to a virus infection which has subsequently caused gradual decrease of neutrophil from 6 months toward 10 months as shown in Fig. 4. Then, infection-associated proinflammatory cytokines may have stimulated the innate immune system to induce primed neutrophils in the persistent increase of neutrophil counts nearly 3 times from the trough to the peak. It is well-known that the primed neutrophils express MPO on the cell surface leading to interact with circulating anti-MPO antibodies which may also bind to Fc $\gamma$ receptors on the neighboring neutrophil surface (1). On the other hand, with regard to the neutrophil life cycle, a persistent increase in the neutrophil counts may probably be associated with an increased number of apoptotic cells, because neutrophils are short-lived cells with a circulatory half-life of several days and their death occurs by apoptosis. An ultrastructural study has shown that unprimed neutrophils in apoptosis express MPO-containing granules on the cell surface making accessible to anti-MPO antibodies (20). Third, it has been shown that soluble MPO released by activated neutrophils binds to unstimulated non-apoptotic neutrophils thereby making them reactive to anti-MPO antibodies (21). It seems likely that certain amounts of serum anti-MPO antibodies were circulating around 17 months (Fig. 4) when a high MPO-ANCA titer was detected, and they might have reacted with MPO diversely expressed on the cell surface of neutrophils, producing ANCA-activated neutrophils. Further, circulating neutrophils with MPO antigens could have caused them to function as antigen presenting cells similar to macrophages and dendritic cells, and thus might have caused higher levels of MPO-ANCA leading to NCGN (22).

At 17 months, a high MPO-ANCA titer of $160 \mathrm{U} / \mathrm{mL}$ was detected as the neutrophil count increased. However, additional inflammatory stimuli appeared to be required to induce NCGN. At 21 months, the upper respiratory infection treated by clarithromycin might have exerted its effect as the predisposing factor needed to induce a very high MPOANCA titer with the development of NCGN at 24 months. Since the serum level of procalcitonin, which is a marker of infection by bacteria, fungi, and parasites, was within the normal range despite the high CRP level at the highest MPO-ANCA titer, the direct participation of these pathogens may be excluded (23). The role of bacterial lipopolysaccharides, concurrent viral infection, or related pro-inflammatory cytokines, such as tumor necrosis factor- $\alpha$, has been suggested for neutrophil priming with further progression to glomerular capillary attachment and respiratory burst (1).

Regarding the care of ANCA-associated vasculitis including RPGN, the usefulness of the routine monitoring of serum ANCA every 2-3 months in remission has been reported (24). We regret that we did not regularly assess MPO-ANCA because the MPO-ANCA titer was relatively low at the first admission and the first renal biopsy did not show NCGN, but instead identified TIN suspicious of sarcoidosis and IgG4-RKD. The present report suggests that precise assessments on serial differential leukocyte counts as well as an incidental upper respiratory infection and repetitive tests on MPO-ANCA may be essential in regular consultations for ANCA-positive patients.

\section{The authors state that they have no Conflict of Interest (COI).}

\section{Acknowledgement}

The authors express their sincere thanks to Mr. Yuji Moritani and Mr. Masayoshi Kadono, Department of Clinical Laboratories, Sugita-Genpaku Memorial Obama Municipal Hospital and Mr. Nobuo Takimoto, Department of Molecular Pathology, University of Fukui.

\section{References}

1. Jennette JC, Nachman PH. ANCA Glomerulonephritis and Vasculitis. Clin J Am Soc Nephrol 12: 1680-1691, 2017.

2. Koyama A, Yamagata K, Makino H, et al. A nationwide survey of rapidly progressive glomerulonephritis in Japan: etiology, prognosis and treatment diversity. Clin Exp Nephrol 13: 633-650, 2009.

3. Kobayashi S, Fujimoto S. Epidemiology of vasculitides: differ- 
ences between Japan, Europe and North America. Clin Exp Nephrol 17: 611-614, 2013.

4. Bomback AS, Appel GB, Radhakrishnan J, et al. ANCAassociated glomerulonephritis in the very elderly. Kidney Int $\mathbf{7 9}$ 757-764, 2011.

5. Goronzy JJ, Li G, Yang Z, Weyand CM. The janus head of T cell aging - autoimmunity and immunodeficiency. Front Immunol 4: 131, 2013.

6. Della-Torre E, Lanzillotta M, Campochiaro C, et al. Antineutrophil cytoplasmic antibody positivity in IgG4-related disease: A case report and review of the literature. Medicine (Baltimore) 95: 34(e 4633), 2016.

7. Hunninghake GW, Costabel U, Ando M, et al. ATS/ERS/WASOG statement on sarcoidosis. American Thoracic Society/European Respiratory Society/World Association of Sarcoidosis and other Granulomatous Disorders. Sarcoidosis Vasc Diffuse Lung Dis 16: 149-173, 1999

8. Crouser ED, Maier LA, Wilson KC, et al. Diagnosis and Detection of Sarcoidosis. An Official American Thoracic Society Clinical Practice Guideline. Am J Respir Crit Care Med 201: e26-e51, 2020.

9. Kraaijvanger R, Janssen Bonas M, Vorselaars ADM, Veltkamp M. Biomarkers in the Diagnosis and Prognosis of Sarcoidosis: Current Use and Future Prospects. Front Immunol 11: 1443, 2020.

10. Tadros M, Forouhar F, Wu GY. Hepatic Sarcoidosis. J Clin Trans Hepatol 1: 87-93, 2013.

11. Sharma OP. Vitamin D, calcium, and sarcoidosis. Chest 109: 535539, 1996.

12. Kawano M, Saeki T, Nakashima H, et al. Proposal for diagnostic criteria for IgG4-related kidney disease. Clin Exp Nephrol 15: 615-626, 2011

13. Matsui S, Hebisawa A, Sakai F, et al. Immunoglobulin G4-related lung disease: clinicoradiological and pathological features. Respirology 18: 480-487, 2013.

14. Tsushima K, Yokoyama T, Kawa S, et al. Elevated IgG4 levels in patients demonstrating sarcoidosis-like radiologic findings. Medicine (Baltimore) 90: 194-200, 2011.

15. Alexander MP, Larsen CP, Gibson IW, et al. Membranous glomerulonephritis is a manifestation of IgG4-related disease. Kid- ney Int 83: 455-462, 2013

16. Stehle T, Audard V, Ronco P, Debiec H. Phospholipase A2 receptor and sarcoidosis-associated membranous nephropathy. Nephrol Dial Transplant 30: 1047-1050, 2015.

17. Hoxha E, Kneissler U, Stege G, et al. Enhanced expression of the M-type phospholipase A2 receptor in glomeruli correlates with serum receptor antibodies in primary membranous nephropathy. Kidney Int 82: 797-804, 2012.

18. Arai H, Toda N, Kamimatsuse R, et al. A refractory case of secondary membranous nephropathy concurrent with IgG4-related tubulointerstitial nephritis. Intern Med 57: 2873-2877, 2018.

19. Sato Y, Boor P, Fukuma S, et al. Developmental stages of tertiary lymphoid tissue reflect local injury and inflammation in mouse and human kidneys. Kidney Int 98: 448-463, 2020.

20. Gilligan HM, Bredy B, Brady HR, et al. Antineutrophil cytoplasmic autoantibodies interact with primary granule constituents on the surface of apoptotic neutrophils in the absence of neutrophil priming. J Exp Med 184: 2231-2241, 1996.

21. Hess C, Sadallah S, Schifferli JA. Induction of neutrophil responsiveness to myeloperoxidase antibodies by their exposure to supernatant of degranulated autologous neutrophils. Blood 96: 28222827, 2000.

22. Vono M, Lin A, Norrby-Teglund A, Koup RA, Liang F, Lore K. Neutrophils aquire the capacity for antigen presentation to memory CD4+ T cells in vitro and ex vivo. Blood: 129: 1991-2001, 2017.

23. Eberhard OK, Haubitz M, Brunkhorst FM, Kliem V, Koch KM, Brunkhorst R. Usefulness of procalcitonin for differentiation between activity of systemic autoimmune disease (systemic lupus erythematosus/systemic antineutrophil cytoplasmic antibodyassociated vasculitis) and invasive bacterial infection. Arthritis Rheum 40: 1250-1256, 1997.

24. Han WK, Choi HK, Roth RM, McCluskey RT, Niles JL. Serial ANCA titers: useful tool for prevention of relapses in ANCAassociated vasculitis. Kidney Int 63: 1079-1085, 2003.

The Internal Medicine is an Open Access journal distributed under the Creative Commons Attribution-NonCommercial-NoDerivatives 4.0 International License. To view the details of this license, please visit (https://creativecommons.org/licenses/ by-nc-nd/4.0/).

(C) The Japanese Society of Internal Medicine Intern Med Advance Publication 